\title{
DERECHOS FUNDAMENTALES E IDEARIO EDUCATIVO CONSTITUCIONAL
}

PABLO NUEVO LÓPEZ 
SUMARIO

I. EL IDEARIO EDUCATIVO CONSTITUCIONAL. II. ESCOLARIZACIÓN OBLIGATORIA Y FINALIDAD DE LA EDUCACIÓN. III. LA CUESTIÓN DE EDUCACIÓN PARA LA CIUDADANÍA Y EL IDEARIO EDUCATIVO CONSTITUCIONAL. IV. LA CUESTIÓN DE LA LEGITIMIDAD DE LOS COLEGIOS ESPECIALIZADOS POR RAZÓN DE SEXO. V. CONCLUSIONES. 


\title{
DERECHOS FUNDAMENTALES E IDEARIO EDUCATIVO CONSTITUCIONAL
}

\author{
PABLO NUEVO LÓPEZ \\ Profesor contratado Doctor de Derecho constitucional \\ Universidad Abat Oliba CEU
}

Es de sobra conocido el hecho de que la elaboración del art. 27 de la Constitución constituyó una de las pruebas más difíciles de superar para lograr el consenso necesario en el proceso constituyente, hasta el punto de que el modo de reconocimiento de los derechos educativos y la libertad de enseñanza motivó que dejara la Ponencia Constitucional el representante del entonces primer partido de la oposición, Sr. Peces-Barba, comprometiéndose así el éxito de la tarea constituyente.

Esto es así porque, como tuvo ocasión de poner de manifiesto Garrido Falla, el art. 27 de la Constitución «cubre en realidad tres problemas clásicos de nuestra historia constitucional: la confesionalidad del Estado, la antítesis clericalismo-anticlericalismo y la oposición enseñanza laica-enseñanza religiosa» ${ }^{1}$.

En este sentido, es sintomático que la práctica totalidad de las leyes de desarrollo del artículo 27 hayan sido impugnadas ante el Tribunal Constitucional. No sólo eso, sino que aquellas leyes que no han sido impugnadas ante el TC por los sujetos legitimados ex art. 162 CE no por ello han estado exentas de polémica política o de oposición jurídica.

Esta conflictividad que ha presidido el ámbito de los derechos educativos no ha estado limitada a los primeros momentos de andadura constitucional ${ }^{2}$, sino

1 GARRIDO FALLA, F. «La elaboración de la Constitución», en M. BALADO y J. A REGUEIRO (dirs.), La Constitución de 1978 en su XXV Aniversario, Bosch, Barcelona, 2003, p. 234.

2 Ya tempranamente pudo sostener Garrido Falla que en la medida en que el artículo $27 \mathrm{CE}$ regula uno de los ámbitos más conflictivos desde el punto de vista político, «es sintomático para 
que ha persistido hasta nuestros días, debiendo ponerse de manifiesto que la conflictividad no se ha limitado al ámbito político, sino que ha trascendido a la sociedad.

En los últimos años hemos asistido a una nueva edición de las «guerras educativas» que cada cierto tiempo asolan nuestro país. Así, tanto el Tribunal Constitucional como la jurisdicción contencioso-administrativa han tenido que pronunciarse sobre cuestiones controvertidas en el ámbito de los derechos educativos al abordar asuntos relacionados con el derecho de los padres a decidir la educación que quieren para sus hijos, habiendo tenido que hacerlo desde la perspectiva del ideario educativo constitucional.

En el presente trabajo, al hilo de dichos pronunciamientos, abordaremos la cuestión del ideario educativo constitucional (I), para ver cómo ha sido interpretado por los Tribunales en relación con la escolarización obligatoria (II), la Educación para la Ciudadanía (III) y el modelo de educación diferenciada (IV), con objeto de concluir en la necesidad de proceder a un entendimiento limitado del ideario educativo constitucional para garantizar la distinción entre Estado y Sociedad y proteger en el ámbito educativo la libertad social.

\section{EL IDEARIO EDUCATIVO CONSTITUCIONAL}

Es un lugar común señalar que la Constitución Española, en materia educativa, no es neutra. El art. $27 \mathrm{CE}$, tras reconocer el derecho a la educación y la libertad de enseñanza, dedica el apartado 2 a establecer los objetivos de la educación, siendo el único artículo del Texto Constitucional en que podemos apreciar referencias a la democracia militante ${ }^{3}$. Al estar la educación al servicio del pleno desarrollo de la personalidad, el art. 27.2 CE deviene la cláusula interpretativa principal de los diferentes contenidos presentes en dicho precepto ${ }^{4}$.

apreciar el grado de consenso que realmente ha presidido la redacción constitucional». GARRIDO FALLA, F. «La salvaguardia de la identidad propia de las escuelas de la Iglesia», Constitución y Acuerdos Iglesia-Estado, Universidad Pontificia de Comillas, Madrid, 1988, p. 201.

3 Cfr. DE OTTO Y PARDO, I. Defensa de la Constitución y partidos políticos, Centro de Estudios Constitucionales, Madrid, 1985, p. 20.

${ }^{4}$ CÁMARA VILLAR, G. «Constitución y Educación (los derechos y libertades del ámbito educativo a los veinte años de vigencia de la Constitución Española de 1978), La experiencia constitucional, 1978-2000, Centro de Estudios Políticos y Constitucionales, Madrid, 2000, p. 271 y ss. Vid., también, ALÁEZ CORRAL, B. «El derecho a la educación del menor como marco delimitador de los criterios de admisión a los centros escolares sostenidos con fondos públicos», en VV. AA., Escolarización del alumnado en el sistema educativo español: cuestiones jurídicas, Fundación Europea Sociedad y Educación, Madrid, 2006, p. 105 y ss. 
Para Sánchez Ferriz y Jimena Quesada, el art. 27.2 debe considerarse «principio rector de todo el sistema educativo», y precisamente por ello «configurador del contenido esencial de la educación» ${ }^{5}$. No sólo eso, sino que es a partir de esta centralidad del art. 27.2 CE como puede abordarse la identificación del ideario educativo constitucional ${ }^{6}$.

Por lo que respecta al contenido del ideario educativo constitucional, el Tribunal Constitucional comenzó a perfilarlo en relación con —y como límite ael ideario de los centros docentes de iniciativa social.

En la STC 5/1981, de 13 de febrero, el Alto Tribunal precisó que

«El derecho a establecer un ideario no está limitado a los aspectos religiosos y morales de la actividad educativa. Dentro del marco de los principios constitucionales, del respeto a los derechos fundamentales, del servicio a la verdad, a las exigencias de la ciencia y a las restantes finalidades necesarias de la educación mencionadas, entre otros lugares, en el art. 27.2 de la Constitución y en el art. 13.1 del Pacto Internacional sobre Derechos Económicos, Sociales y Culturales (...)» (FJ 8).

En el Voto particular formulado a esta Sentencia, el Magistrado Sr. D. Francisco Tomás y Valiente considera que la referencia del art. 27.2 CE al libre desarrollo de la personalidad como objeto de la educación implica necesariamente que ésta deba realizarse en libertad, de lo cual deduce que deba formarse a los alumnos «en el respeto a los principios democráticos de convivencia y a los derechos y libertades fundamentales», por lo que deben considerarse contrarios a la Constitución «idearios educativos totalitarios o antidemocráticos» (Núm. 10 del Voto particular). Asimismo, consideró este Magistrado que el libre desarrollo de la personalidad de los educandos «se obtiene fomentando en ellos un espíritu crítico, que sólo es posible imbuirles si también los profesores hacen uso de él en sus explicaciones» (Núm. 16 del Voto particular).

De este modo, a juicio de Tomás y Valiente el espíritu crítico transmitido en la educación permitiría la autodeterminación que se desprende del valor libertad constitucionalizado en el art. 1.1 CE.

5 SÁNCHEZ FERRIZ, R., y JIMENA QUESADA, L., La enseñanza de los derechos humanos, Ariel, Barcelona, 1995, p. 77.

${ }^{6}$ NUEVO LÓPEZ, P. La Constitución educativa del pluralismo. Una aproximación desde la teoría de los derechos fundamentales, NetBiblo-UNED, La Coruña, 2009, pp. 53-71. 
Lo señalado por Tomás y Valiente en su Voto particular de 1981 parece inspirar la posición del Tribunal en su Auto 40/19997 , de 22 de febrero, en el cual el TC señaló que, con la educación,

«se trata de asegurar que los alumnos reciban una formación adecuada para el pleno desarrollo de su personalidad, proporcionándoles el bagaje cultural necesario para el legítimo y pleno ejercicio de su libertad ideológica, comprensiva de todas las opciones que suscita la vida personal y social» (FJ 2).

En un sentido similar, el Tribunal Supremo tuvo ocasión de pronunciarse en relación con el ideario educativo constitucional. Así, en su Sentencia de 31 de enero de 1997 (Ar. 597), afirmó al respecto lo siguiente

«Es observable que tanto los sujetos como el objeto de la educación están perfectamente sistematizados en los apartados 1 y 2 y que de este sistema no puede excluirse el hecho de que a la finalidad de la educación se le asigna por el Texto Constitucional un contenido que bien merece la calificación de moral, entendida esta noción en un sentido cívico y aconfesional: pleno desarrollo de la personalidad humana en el respeto a los principios democráticos de convivencia y a los derechos y libertades fundamentales» (FJ 2).

Precisamente por esto, desde el primer momento la doctrina ha sido unánime al considerar el carácter moral ${ }^{8}$ o la dimensión ética de la educación, la cual entonces debe extenderse a la formación general del individuo ${ }^{9}$. Y, en consecuencia, el art. 27.2 CE no constituye únicamente un límite a otras libertades presentes en el ámbito educativo (como la libertad de cátedra de los docentes o la de establecimiento de un ideario de los titulares de los centros educativos), sino que implica «un compromiso positivo y la necesidad de inspirar todo el proceso educativo» ${ }^{10}$.

Ahora bien, hasta fechas recientes no se ha prestado demasiada atención al objeto de la educación en el art. 27 y su proyección en el ideario educativo cons-

7 Si bien en este Auto el TC se refiere a las materias alternativas a la clase de Religión, considero que su argumentación puede ser extrapolada a la educación en general, ex art. 27.2 CE.

$8 \mathrm{Al}$ respecto, Cfr. GARRIDO FALLA, F. «Artículo 27», en F. GARRIDO FALLA (dir.), Comentarios a la Constitución, Civitas, Madrid, 1985, pp. 550 y ss.; MARTÍNEZ DE PISÓN, J. El derecho a la educación y la libertad de enseñanza, Dykinson, Madrid, 2006, pp. 126 y ss.; BARNÉS, J. «La educación en la Constitución. Una reflexión conciliadora», Revista Española de Derecho Constitucional, núm. 12, 1984, pp. 40 y ss.

9 PÉREZ ROYO, J. Curso de Derecho Constitucional, Marcial Pons, Madrid, 2000, p. 254.

10 FERNÁNDEZ-MIRANDA, A. De la libertad de enseñanza al derecho a la educación. Los derechos educativos en la Constitución Española, Centro de Estudios Ramón Areces, Madrid, 1988, p. 51. 
titucional. La mayoría de las referencias doctrinales al respecto se encuentran en trabajos en los que los autores abordaban las cuestiones controvertidas en relación con el art. 27, a saber: conflictos entre ideario de los centros docentes y la libertad de cátedra, la alternativa a la clase de Religión, los límites de los titulares de los centros docentes de iniciativa social, etc. De ahí que Cámara Villar llegara a señalar que en el art. 27.2 CE era posible encontrar «la máxima expresión del consenso básico sobre la educación ${ }^{11}$.

No obstante, y a la luz de las polémicas que últimamente han existido en relación con el objeto de la educación, quizá no estuviéramos tanto ante un «consenso básico» acerca de que la educación tendrá por objeto el pleno desarrollo de la personalidad sino ante un consenso básico en no explicitar el desacuerdo $^{12}$ sobre qué se entiende por pleno desarrollo de la personalidad ${ }^{13}$.

Como ya hemos señalado anteriormente, en los últimos tiempos los Tribunales han tenido que pronunciarse sobre cuestiones en las que está en discusión, precisamente, cómo puede alcanzarse el pleno desarrollo de la personalidad por medio de la educación, y de modo reflejo en qué consiste el ideario educativo constitucional. En efecto, al hilo de conflictos sobre la obligatoriedad o no de la escolarización, la posibilidad de objetar por razones de conciencia a la obligación de cursar una asignatura o la renovación del concierto a centros especializados por razón del sexo del alumnado, tanto el TC como los Tribunales de la Jurisdicción Contencioso-Administrativa han debido encarar la cuestión de la finalidad de la educación y el ideario educativo constitucional.

${ }^{11}$ CÁmARA VILLAR, G. «Sobre el concepto y los fines de la educación en la Constitución Española», Introducción a los derechos fundamentales: X Jornadas de Estudio, Ministerio de Justicia, Madrid, Vol. III, 1989, pp. 2168-2171.

${ }_{12}$ Por lo que se refiere a las fórmulas de consenso en el Texto Constitucional, vid. SÁNCHEZAGESTA, L. Sistema político de la Constitución Española de 1978, Editora Nacional, 1981, pp. 95 a 98. Entre los tipos de fórmulas de consenso en nuestra Norma Constitucional Sánchez-Agesta identifica la «ambigüedad en la expresión», entre las que cita el «problema de la educación».

${ }^{13}$ En uno de los primeros estudios sistemáticos de la Constitución, Prieto Sanchís ya advirtió que, aunque el art. 27.2 CE «formalmente no es materia controvertida», de ello no se deriva que «exista un acuerdo de fondo acerca de cuáles han de ser los objetivos de la enseñanza ni de cómo ha de lograrse el pleno desarrollo de la personalidad humana». Cfr. PRIETO SANCHÍS, L. «Las relaciones Iglesia-Estado a la luz de la nueva Constitución: problemas fundamentales», en A. PEDRIERI y E. GARCÍA DE ENTERRÍA (dirs.) La Constitución Española de 1978, Civitas, Madrid, 1981, p. 364. 


\section{ESCOLARIZACIÓN OBLIGATORIA Y FINALIDAD DE LA EDUCACIÓN}

Con su Sentencia 133/2010, de 2 de diciembre, el Tribunal Constitucional resolvió el recurso de amparo interpuesto por cuatro padres contra una Sentencia de la Audiencia Provincial de Málaga, de fecha 6 de junio de 2005, confirmatoria de la Sentencia de 5 de mayo de 2003 del Juzgado de Primera Instancia núm. 2 de Coín.

En la Sentencia del Juzgado de Primera Instancia de Coín, y a instancias del Ministerio Fiscal, los padres fueron condenados a escolarizar a sus respectivos hijos menores de edad. En opinión del Juzgado, si bien puede convenirse que la enseñanza que recibían los hijos de los recurrentes es de calidad ${ }^{14}$, el art. 27.4 CE no permite la educación en casa o bome schooling, siendo relevante para el órgano judicial que la exclusión del sistema oficial de educación puede generar problemas a los menores, ya sea en el ámbito académico ya sea en el social, por las dificultades de integración con otros niños de su edad.

Recurrida dicha Sentencia por los padres, la Audiencia Provincial de Málaga desestimó el recurso, señalando que forma parte del contenido básico del derecho a la educación la escolarización, sin que los padres sean titulares de un derecho a decidir que sus hijos reciban la educación en casa. Frente a esta Sentencia los padres interpusieron el correspondiente recurso de amparo ante el Tribunal Constitucional ${ }^{15}$.

Por lo que respecta a la vulneración del derecho a la educación, los padres recurrentes sostenían que las resoluciones impugnadas denegaban a los menores el derecho a seguir su proceso educativo en su propio domicilio, sin integrarse en el sistema escolar.

En su Sentencia, el TC desestimó el recurso de amparo de los padres. Por lo que se refiere a los derechos educativos de los padres, considera el Alto Tribunal que la «facultad de los padres de elegir para sus hijos una educación ajena al sistema de escolarización obligatoria por motivos de orden pedagógico no está comprendida, ni siquiera prima facie, en ninguna de las libertades constitucionales que la demanda invoca y que el art. 27 CE reconoce» (FJ 5). Esto es así,

${ }^{14}$ Los hijos de los recurrentes, que recibían educación en el propio domicilio, hablaban cinco idiomas y recibían clases de música, matemáticas, ciencias y lengua.

15 En dicho recurso los padres alegaban vulneración del derecho a la tutela judicial efectiva sin indefensión, del derecho a un proceso con todas las garantías, del derecho a la educación y del derecho a la igualdad de trato en el orden jurídico. Teniendo en cuenta el objeto del presente trabajo, nos centraremos sólo en aquello que guarda relación con el derecho a la educación y el ideario educativo constitucional. 
sostiene el Alto Tribunal, porque «la libertad de enseñanza de los padres encuentra su cauce específico de ejercicio, por expresa determinación constitucional, en la libertad de creación de centros docentes», pudiendo caracterizar pedagógicamente a los mismos, aparte de que el derecho de los padres a elegir la educación que quieren para sus hijos se concreta en el derecho de elección de centro docente y en el derecho a elegir la formación moral y religiosa que sus hijos han de recibir. De manera que la dimensión de derecho de libertad del derecho a la educación no protege «una pretendida facultad de los padres de elegir para sus hijos por razones pedagógicas un tipo de enseñanza que implique su no escolarización en centros homologados de carácter público o privado» (FJ 5).

Junto a estos argumentos, el TC añade otros que conducen asimismo a la desestimación del recurso de amparo: aun cuando pudiera considerarse que el derecho de los padres incluye, prima facie, la posibilidad de decidir sobre la escolarización o no de sus hijos, la obligación establecida en las leyes educativas de proceder a la escolarización de todos los menores entre los seis y los dieciséis años sería una restricción proporcionada de ese derecho, precisamente por constituir una concreción legislativa del ideario educativo constitucional.

Para ello, el Tribunal Constitucional debe encarar la cuestión de la finalidad de la educación, en función de la cual cobra sentido — puede justificarse — la escolarización obligatoria y la prohibición del llamado bome schooling.

Así, junto a la transmisión de conocimientos, para el Alto Tribunal la referencia del art. 27.2 CE al libre desarrollo de la personalidad hace que debamos considerar dentro de las finalidades de la educación la «formación de ciudadanos responsables llamados a participar en los procesos que se desarrollan en el marco de una sociedad plural» (FJ 7). En consecuencia, el legislador está habilitado — si bien tampoco se encuentra obligado a ello, como señala expresamente el Tribunal en su FJ 9- para imponer la escolarización obligatoria como medio de conseguir el objetivo de formar «ciudadanos respetuosos con los principios democráticos de convivencia y con los derechos y libertades fundamentales», en la medida en que esta finalidad

«se ve satisfecha más eficazmente mediante un modelo de enseñanza básica en el que el contacto con la sociedad plural y con los diversos y heterogéneos elementos que la integran, lejos de tener lugar de manera puramente ocasional y fragmentaria, forma parte de la experiencia cotidiana que facilita la escolarización» $(\mathrm{FJ} 8)^{16}$.

${ }^{16} \mathrm{~A}$ mi entender, este argumento es en cierto modo contradictorio con el expuesto por el Tribunal en el FJ 5 de la misma Sentencia. Si uno de los medios que tienen los padres de proporcionar a sus hijos una educación de acuerdo con sus convicciones pedagógicas es, precisamente, la 
Es decir, del ideario educativo constitucional se desprende que los poderes públicos deben garantizar a todos el acceso a una formación adecuada para el pleno desarrollo de su personalidad, de manera que los alumnos tengan a su alcance «el bagaje cultural necesario para el legítimo y pleno ejercicio de su libertad» (ATC 40/1999, FJ 2), sino que están habilitados para regular la dimensión prestacional del derecho a la educación de tal manera que ésta sea apta para formar ciudadanos ${ }^{17}$.

De hecho, sólo enfatizando la finalidad socializadora de la educación puede limitarse el recurso a la educación en casa. A este respecto, quizá nos encontremos - si no ante un cambio de jurisprudencia del TC - al menos ante una profundización de su doctrina en este aspecto de la educación. En este sentido, debe resaltarse cómo no hace demasiado tiempo la doctrina sostenía que el deber de recibir educación establecido en el art. 27.4 CE «no tiene otra finalidad que la de satisfacer un derecho individual, no, por ejemplo, la de favorecer la integración social» ${ }^{18}$, consideración de la que se derivaba la licitud de la educación en el propio hogar. Del mismo modo, Díez-Picazo sostenía que «el único modo de argumentar que la Constitución prohíbe el home schooling sería afirmar que el deber de cursar la enseñanza básica no solo tiene por objetivo dotar al niño de conocimientos indispensables, sino también socializarlo en una escuela con otros niños; pero, por razonable que sea esta idea, no se alcanza a ver cuál sería su apoyatura constitucional $\gg^{19}$.

creación de centros docentes pedagógicamente caracterizados, es razonable esperar que en un centro así los padres que optan por él para la educación de sus hijos sean aquellos que comparten las convicciones de quienes han creado el citado centro. Por lo que es cuando menos dudoso que así se consiga «el contacto con la sociedad plural y con los diversos y heterogéneos elementos que la integran». De llevarse este argumento del TC a sus últimas consecuencias, el modelo educativo apto para formar ciudadanos sería el de la escuela «única, pública y laica», lo cual no se compadece con la regulación constitucional de los derechos educativos.

17 Una crítica a esta Sentencia puede verse en MARTÍ SÁNCHEZ, J. M. ${ }^{a}$ «El home schooling en el Derecho español», Revista General de Derecho Canónico y Derecho Eclesiástico del Estado, núm. 25, 2011, donde expresamente señala que «el pluralismo (relativista) puede ser un lastre en la conciencia del menor», aparte de resaltar, a la luz de los hechos del caso controvertido, lo siguiente: «¿se piensa seriamente que una familia que ha enseñado cinco idiomas a sus hijos no les ha preparado para «el contacto con la sociedad plural»? ¿Se desconoce que esas mismas familias se salen, por su composición y riqueza, de lo que es habitual en nuestra sociedad? Las lenguas son la puerta de acceso a una cultura. La familia es la clave de la formación», p. 35.

18 RUBIO LLORENTE, F. «Los deberes constitucionales», Revista Española de Derecho Constitucional, núm. 62, 2001, p. 29.

19 DÍEZ-PICAZO, L. M. ${ }^{a}$ Sistema de derechos fundamentales, 3. a ed., Madrid, Thomson Civitas, 2008, p. 495. 
Es cierto que, en determinados países, la educación en casa es una práctica particularmente extendida en - y en ocasiones casi limitada a- grupos religiosos minoritarios dotados de una fuerte identidad. Esto lleva a Valero Heredia a sostener que el ideario educativo constitucional «requiere la puesta en práctica de un contexto educativo basado en los principios de apertura e integración social, que ofrezca a los alumnos una visión del mundo lo menos sesgada posible», concluyendo esta autora que «la enseñanza en casa o en el seno de grupos fuertemente ideologizados, no parece el medio más adecuado para dar satisfacción al ideario constitucional del artículo 27.2 $\mathrm{CE}{ }^{20}$.

Pero, en mi opinión, esto no debe llevar a ver con recelo este tipo de educación, como si siempre conllevara un planteamiento sesgado que incapacitara para el desarrollo de una vida normal en tanto que ciudadano. De un lado porque no siempre quienes deciden educar a sus hijos en casa pertenecen a un grupo fuertemente ideologizado, en el sentido descrito por Valero Heredia; de hecho, claramente no era el caso de los recurrentes en la Sentencia del Tribunal Constitucional 133/2010, única habida hasta la fecha en la que el Alto Tribunal ha debido abordar de frente esta problemática. Pero, de otro, porque no siempre la educación en el seno de un grupo religioso o ideológico comporta, en sí misma, incapacidad para la integración social.

De hecho, debe ponerse de manifiesto que el Tribunal Constitucional, en su Sentencia 133/2010, lo que señaló es que el derecho a optar por la educación en casa no forma parte de los derechos de los padres protegidos por el art. $27 \mathrm{CE}$, no que este tipo de educación fuera, necesariamente, contraria al ideario educativo constitucional. Así, expresamente afirmó que

«La Constitución española no prohíbe al legislador democrático configurar la enseñanza básica obligatoria (art. 27.4 CE) como un periodo de escolarización de duración determinada (cfr. arts. 9.2 LOCE y 4.2 LOE) durante el cual quede excluida la opción de los padres de enseñar a sus hijos en su propio domicilio en lugar de proceder a escolarizarlos. Según se ha comprobado, esa configuración legislativa no afecta en el caso presente a los derechos constitucionales de los padres (art. 27.1 y 3 CE), e incluso en el caso de que así lo hiciera habría de considerarse una medida proporcionada que encuentra justificación en la satisfacción de otros principios y derechos constitucionales (art. 27.1 y 2 CE). Con todo, ésta no es una opción que venga en todo caso requerida por la propia Constitución que, efectivamente, no consagra directamente el deber de escolarización, ni mucho menos otros aspectos más concretos de su régimen jurídico como, por

20 VALERO HEREDIA, A. «Ideario educativo constitucional y «homeschooling»: a propósito de la Sentencia del Tribunal constitucional 133/2010, de 2 de diciembre», Revista Española de Derecho Constitucional, núm. 94, 2012, p. 437. 
ejemplo, la duración del periodo sobre el que ha de proyectarse o las circunstancias excepcionales en las que dicho deber pueda ser dispensado o verse satisfecho mediante un régimen especial. Quiere ello decir que, a la vista del art. $27 \mathrm{CE}$, no cabe excluir otras opciones legislativas que incorporen una cierta flexibilidad al sistema educativo y, en particular, a la enseñanza básica, sin que ello permita dejar de dar satisfacción a la finalidad que ha de presidir su configuración normativa (art. 27.2 CE) así como a otros de sus elementos ya definidos por la propia Constitución (art. 27.4, 5 y 8 CE)» (FJ 9).

Si, a juicio del Alto Tribunal, la escolarización obligatoria no está «en todo caso requerida por la propia Constitución» y el legislador puede flexibilizar el sistema educativo abriendo la posibilidad a la educación en casa, debe concluirse que ésta no es, siempre y en todo caso, contraria al ideario educativo constitucional $^{21}$. De modo que, a mi entender, no puede concluirse a partir de la citada Sentencia 133/2010 que el fin constitucional de la educación «no puede garan-

${ }^{21}$ A modo de ejemplo, puede citarse el art. 55 de la Ley 12/2009, del 10 de julio, de educación de Cataluña. Este precepto establece lo siguiente:

1. El Gobierno, para facilitar el derecho universal a la educación, debe desarrollar una oferta adecuada de educación no presencial.

2. Se pueden impartir en la modalidad de educación no presencial las enseñanzas postobligatorias, las enseñanzas que no conducen a titulaciones o certificaciones con validez en todo el Estado, los cursos de formación preparatoria para las pruebas de acceso al sistema educativo, la formación en las competencias básicas, la formación para el empleo y la formación permanente. También pueden impartirse en dicha modalidad, excepcionalmente, enseñanzas obligatorias y las demás enseñanzas que, en determinadas circunstancias, establezca el Departamento.

3. La oferta educativa no presencial debe caracterizarse por la variedad, la apertura y la flexibilidad para alcanzar, especialmente, la extensión de la accesibilidad de esta formación, la simultaneidad con otras enseñanzas y la complementariedad con otras acciones y estrategias formativas, así como la compatibilidad con el trabajo.

4. Sin perjuicio de las modalidades de formación semipresencial y no presencial que puedan implantarse en los centros públicos ordinarios, la Administración educativa debe organizar a través de un centro singular la impartición específica de las enseñanzas en la modalidad de educación no presencial.

5. El profesorado que imparte enseñanzas en la modalidad de educación no presencial debe poseer la titulación requerida para cada etapa educativa y debe acreditar la capacitación para ejercer la docencia utilizando medios telemáticos y los otros recursos propios de la educación no presencial.

6. El Departamento puede autorizar a los centros privados a impartir enseñanzas postobligatorias y enseñanzas superiores en la modalidad de educación no presencial.

7. El Departamento debe crear y regular un registro en el que consten los datos de los alumnos que se acogen a la modalidad de educación no presencial en enseñanzas de educación básica. 
tizarse apartando al menor en su proceso formativo de la sociedad abierta y plural en la que ha de convivir» ${ }^{22}$.

En cualquier caso, si los poderes públicos son competentes para incluir dentro de la finalidad constitucional de la educación la formación de ciudadanos es preciso analizar hasta dónde alcanza esta competencia, pues como tempranamente puso de manifiesto el TC en su Sentencia 5/1981, de 13 de febrero, «en un sistema jurídico político basado en el pluralismo, la libertad ideológica y religiosa de los individuos y la aconfesionalidad del Estado, todas las instituciones públicas y muy especialmente los centros docentes, han de ser, en efecto, ideológicamente neutrales» (FJ 9), estando expresamente vedado todo tipo de adoctrinamiento ideológico en los centros docentes.

\section{LA CUESTIÓN DE EDUCACIÓN PARA LA CIUDADANÍA Y EL IDEARIO EDUCATIVO CONSTITUCIONAL}

Precisamente esta cuestión del alcance de la competencia estatal en la definición de la competencia ciudadana en el ámbito de la educación obligatoria ha estado rodeado de una intensa polémica en los últimos años en España. En este sentido, es notorio el conflicto social que originó la introducción en los currículos educativos del conjunto de asignaturas agrupadas en la materia de Educación para la Ciudadanía ${ }^{23}$.

22 VALERO HEREDIA, A. «Ideario educativo constitucional y «homeschooling»: a propósito de la Sentencia del Tribunal constitucional 133/2010, de 2 de diciembre», Op. cit., p. 442. En sentido semejante se expresa Aláez Corral, quien considera incompatible el homeschooling por la «necesidad de socialización democrática del menor»; así, vid., ALÁEZ CORRAL, B. «El ideario educativo constitucional como límite a las libertades educativas», Revista Europea de Derechos fundamentales, núm. 17, 2011, p. 93.

${ }^{23}$ La Ley Orgánica 8/2013, de 9 de diciembre, para la mejora de la calidad educativa (LOMCE) ha procedido a modificar la LOE en este punto, optando, de acuerdo con el apartado XIV de la Exposición de motivos, por «incorporar la educación cívica y constitucional a todas las asignaturas durante la educación básica, de forma que la adquisición de competencias sociales y cívicas se incluya en la dinámica cotidiana de los procesos de enseñanza y aprendizaje y se potencie de esa forma, a través de un planteamiento conjunto, su posibilidad de transferencia y su carácter orientador», abordando esta cuestión por tanto de manera transversal y no mediante la incorporación de un conjunto de asignaturas al currículo obligatorio. Por lo que respecta al régimen previo a la LOMCE, la intensidad de la polémica puede apreciarse en los mismos datos: más de 52.000 objeciones de conciencia a las asignaturas de Educación para la Ciudadanía, más de 2000 recursos contenciosoadministrativos presentados contra las denegaciones de la objeción por las distintas administraciones educativas autonómicas, etc. Aun cuando la polémica relacionada con esta materia disminuyó a partir de 2009 (año en que el Tribunal Supremo declaró que no existe en nuestro ordenamiento el derecho a la mencionada objeción de conciencia), el conflicto jurídico sigue. En el momento de 
De hecho, ya durante la tramitación parlamentaria de la Ley orgánica 2/2006, de 3 de mayo, de Educación (en adelante, LOE), un sector de la doctrina subrayó el carácter potencialmente adoctrinador de la materia Educación para la Ciudadanía ${ }^{24}$. Sin entrar en la cuestión acerca de la objeción de conciencia a las diferentes asignaturas englobadas en la materia Educación para la Ciudada$n^{2} a^{25}$, la polémica jurídica originada por esta controvertida materia ha servido también para ayudar a clarificar el ideario educativo constitucional ${ }^{26}$.

De entrada, ya con ocasión de la aprobación por el Gobierno de los Reales Decretos reguladores de los contenidos mínimos de Educación Primaria ${ }^{27}$ y Educación Secundaria Obligatoria ${ }^{28}$ el Consejo de Estado procedió a enmarcar el contenido que podía tener la materia de Educación para la Ciudadanía para cumplir con la finalidad de formar ciudadanos sin vulnerar la obligación de neutralidad ideológica.

escribir este trabajo, está pendiente ante el Tribunal Europeo de Derechos Humanos una demanda interpuesta contra España por más de 500 padres objetores. Los principales hitos de esta polémica, descritos desde la perspectiva de los grupos sociales que impulsaron la objeción de conciencia, pueden consultarse en ¡Ni un paso atrás! La lucha de los padres frente a Educación para la Ciudadanía, Profesionales por la Ética, Criteria Club de lectores, Madrid, 2009. El libro puede descargarse gratuitamente en el siguiente enlace: http://www.profesionalesetica.org/wp-content/ uploads/2013/01/PROFESIONALES-POR-LA-ETICA-Ni-un-paso-atras.pdf (fecha última de consulta: 16 de diciembre de 2013).

${ }^{24}$ Cfr. MARTÍ SÁNCHEZ, José María, «La educación para la ciudadanía en el sistema de la Ley Orgánica de Educación (Una reflexión desde la libertad religiosa)», Revista General de Derecho Canónico y Derecho Eclesiástico del Estado, núm. 10, 2006. Del mismo autor, vid. también, «La Educación para la Ciudadanía: Ley Orgánica 2/2006, de Educación», Anuario de Derecho Eclesiástico del Estado, núm. 23, 2007, pp. 211-255.

${ }^{25}$ Cfr. sobre este tema, EMBID IRUJO, A. «La educación para la ciudadanía en el sistema educativo español. Reflexiones jurídicas», Revista Española de Derecho Constitucional, núm. 83, 2008, pp. 11-56; EMBID IRUJO, A. «Educar a ciudadanos. Reflexiones en torno a las Sentencias del Tribunal Supremo de 11 de febrero de 2009 sobre la "Educación para la ciudadanía" », El Cronista del Estado social y democrático de derecho, núm. 4, 2009, pp. 40-49. RUANO ESPINA, L. «Las Sentencias del Tribunal Supremo de 11 febrero de 2009 sobre objeción de conciencia a EPC», Revista General de Derecho Canónico y Derecho Eclesiástico del Estado, núm. 20, 2009. MARTÍ SÁNCHEZ, J. M. " "Objeciones de conciencia y escuela», Revista General de Derecho Canónico y Derecho Eclesiástico del Estado, núm. 15, 2007.

${ }^{26}$ Un análisis de la jurisprudencia recaída sobre esta materia puede verse en GÓMEZ ORFANEL, G. «Jurisprudencia española sobre educación para la ciudadanía», Anuario de Derechos Humanos (Nueva época), Vol. 10, 2009, pp 261-283.

27 Real Decreto 1513/2006, de 7 de diciembre, por el que se establecen las enseñanzas mínimas de la Educación Primaria (BOE de 8 de diciembre de 2006).

${ }^{28}$ Real Decreto 1631/2006, de 29 de diciembre, por el que se establecen las enseñanzas mínimas correspondientes a la Educación Secundaria Obligatoria (BOE de 5 de enero de 2007). 
En los Dictámenes emitidos con ocasión del examen de los Proyectos de los mencionados Reales Decretos ${ }^{29}$, el Consejo de Estado partió de la distinción entre lo constitucionalmente lícito y lo constitucionalmente obligatorio. A la luz de esta distinción, el Consejo de Estado consideró que no es lícita «la difusión de valores que no estén consagrados en la propia Constitución o sean presupuesto o corolario indispensables del orden constitucional».

Por el contrario, todo lo que no sea «corolario indispensable» del orden constitucional o valores «consagrados en la propia Constitución», aun cuando sea constitucionalmente lícito (es decir, que en virtud del valor pluralismo político reconocido en el art. 1.1 CE quede a disposición de los poderes públicos competentes) debe quedar fuera del contenido que el poder normativo dé a la educación para conseguir la finalidad de formar ciudadanos ${ }^{30}$.

A un resultado semejante llegó el Tribunal Supremo, en sus Sentencias de 11 de febrero de 2009, en relación con la objeción de conciencia a Educación para la Ciudadanía ${ }^{31}$.

Para el Tribunal Supremo, del orden constitucional y la finalidad de la educación establecida en la Constitución se deriva que la educación es «esencial instrumento para garantizar» el pluralismo en la sociedad, en la medida en que «transmite a los alumnos la realidad de esa diversidad de concepciones sobre la vida individual y colectiva, como asimismo les instruye sobre su relevancia, para que sepan valorar la trascendencia de esa diversidad y, sobre todo, aprendan a respetarla». Asimismo, teniendo en cuenta la centralidad de los derechos fundamentales en el orden constitucional — consecuencia de lo dispuesto en el art. $10 \mathrm{CE}-$ considera el TS que «la actividad educativa no podrá desentenderse de transmi-

29 Dictámenes 2234/2006, de 23 de noviembre, en relación con el Proyecto de Real Decreto por el que se establecen las enseñanzas mínimas de Educación Primaria, y 2521/2006, de 21 de diciembre, en relación con el Proyecto de Real Decreto por el que se establecen las enseñanzas mínimas correspondientes a la Educación Secundaria Obligatoria.

${ }^{30}$ Cfr. NUEVO LÓPEZ, P. «La introducción de la asignatura "Educación para la Ciudadanía" y la concepción constitucional del pluralismo político», Cuadernos constitucionales de la Cátedra Fadrique Furió Ceriol, núm. 56, 2006, pp. 74-78.

${ }^{31}$ Las citas que siguen del Tribunal Supremo corresponden al Fundamento Jurídico 6 de la Sentencia dictada con ocasión del Recurso de Casación núm. 948/2008 (Ponente: Excmo. Sr. Pablo Lucas Murillo de la Cueva). En idénticos términos se expresó el Tribunal Supremo en las Sentencias de la misma fecha 11 de febrero de 2009, dictadas con ocasión de los Recursos de Casación núm. 1013/2008 (Ponente: Excmo. Sr. Nicolás Maurandi Guillén), 949/2008 (Ponente: Excmo. Sr. Ramón Trillo Torres) y 905/2008 (Ponente: Excmo. Sr. Luis M. ${ }^{a}$ Díez-Picazo Giménez). Con posterioridad, el Tribunal Supremo ha dictado numerosas Sentencias sobre la misma cuestión, repitiendo la doctrina elaborada en las de 11 de febrero de 2009. 
tir los valores morales que subyacen en los derechos fundamentales o son corolario esencial de los mismos».

Esto es así porque hay una necesaria «vinculación entre enseñanza y democracia», pues la democracia «además de ser un mecanismo formal para la constitución de los poderes públicos, es también un esquema de principios y valores».

De esta relación entre enseñanza y democracia el TS deduce que la intervención pública en materia educativa «tiene como fin no sólo (1) asegurar la transmisión del conocimiento del entramado institucional del Estado, sino también (2) ofrecer una instrucción o información sobre los valores necesarios para el buen funcionamiento del sistema democrático», proyectándose esta intervención tanto a los centros públicos como a los privados.

Ahora bien, debe distinguirse el modo de enseñar los valores que subyacen al orden democrático constitucional. En opinión del Tribunal Supremo, aquellos «valores que constituyen el sustrato moral del sistema constitucional y aparecen recogidos en normas jurídicas vinculantes» no sólo «será constitucionalmente lícita su exposición», sino incluso llevarla a cabo «en términos de promover la adhesión a los mismos». Por el contrario, en relación con el pluralismo (atendiendo a las «principales concepciones culturales, morales o ideológicas que, más allá de ese espacio ético común, pueden existir en cada momento histórico dentro de la sociedad»), la acción educativa deberá limitarse a informar y a «transmitir a los alumnos la necesidad de respetar las concepciones distintas a las suyas pese a no compartirlas».

En este segundo caso debe exigirse neutralidad al poder público, de modo que la información sea transmitida «de manera rigurosamente objetiva, con la exclusiva finalidad de instruir o informar sobre el pluralismo realmente existente en la sociedad acerca de determinadas cuestiones que son objeto de polémica». En cambio, cuando se trate de los valores que subyacen al orden democrático constitucional la acción del Estado puede llegar hasta el punto de «fomentar sentimientos y actitudes que favorezcan su vivencia práctica».

La argumentación del Tribunal Supremo es en parte compartida en este punto por Aláez Corral, para quien el derecho a la educación «no es neutro desde un punto de vista moral y debe orientarse positivamente a la impregnación del educando de ciertos valores que constituyen una moral cívico-democrática», de lo que se deriva la imposible neutralidad axiológica del Estado. Esto, inevitablemente, lleva a algún tipo de «adoctrinamiento», que en opinión de este autor será lícito si se mantiene dentro de «los valores democráticos del pluralis- 
mo, la libertad y la igualdad $»^{32}$. Y esto porque estos valores «representan los valores mínimos a observar en la convivencia social democrática, y los medios necesarios para la realización de la dignidad de la persona, pues hacen que a los alumnos se les inculque el respeto a su propia dignidad y a la de los demás» ${ }^{33}$.

Sentado lo anterior, en opinión de Aláez cabe extraer alguna conclusión adicional a las del Tribunal Supremo a la hora de relacionar el ideario educativo constitucional con los derechos educativos. De un lado, considera este autor que el ideario educativo constitucional se proyecta sobre la dimensión de prestación del derecho a la educación en el sentido de permitir al individuo «exigir de los poderes públicos la organización de un sistema educativo que realice individualmente la recepción (en su caso gratuita) no sólo de una educación que transmita conocimientos de forma libre y plural, sino también que forme cívico-moralmente a la persona dentro de los valores democráticos» ${ }^{34}$.

Ahora bien, como señalan Naval y González, «poner los derechos humanos como fuente ética de la educación cívica no determina cómo realizar ésta prácticamente» ${ }^{35}$, debiendo tenerse en cuenta la apreciación de Barrio Maestre, para quien la raíz ética de la educación cívica «se percibe claramente en una mutua interdependencia de las dimensiones de la justicia, tal como lo entendieron los juristas latinos: el suum quique tribuere y el alterum non laedere son radicalmente inseparables del boneste vivere» ${ }^{36}$.

De ahí que en una «aproximación metodológica al problema de los contenidos» de Educación para la Ciudadanía (sin entrar, por tanto, en el análisis de los Reales Decretos de contenidos mínimos), Fernández-Miranda ha sostenido que para ser constitucionalmente adecuada, la asignatura puede incluir «contenidos éticos constitucionalmente garantizados», esto es «aquellos valores y principios cuyo alcance se desprende pacíficamente de la interpretación doctrinal o jurisprudencial», debiendo eludir «todas aquellas cuestiones que en una Constitución

32 ALÁEZ CORRAL, B. «Ideario educativo constitucional y respeto a las convicciones morales de los padres: a propósito de las sentencias del Tribunal Supremo sobre "Educación para la ciudadanía”, El Cronista del Estado Social y Democrático de Derecho, núm. 5, 2009.

33 ALÁEZ CORRAL. B. «Caso Folgero y respeto a las convicciones morales de los padres en materia educativa», Repertorio Aranzadi del Tribunal Constitucional, núm. 3, 2008.

34 ALÁEZ CORRAL, B. «El ideario educativo constitucional como límite a las libertades educativas», Op. cit., p. 96.

35 GONZÁLEZ, M. y NAVAL, C., «Una aproximación a la educación para la ciudadanía en Europa en la última década», La educación cívica hoy. Una perspectiva interdisciplinar, NAVAL, C. y LASPALAS, J. (eds.), EUNSA, Pamplona, 2000, p. 232.

36 BARRIO MAESTRE, J. M. «Educación para los derechos humanos», Hacia una cultura de los derechos humanos. Universidad de Verano de derechos humanos y del derecho a la educación, FERNÁNDEZ, A. (ed.), Ginebra, 2000, p. 144. 
abierta no pasarán nunca de ser opciones legítimas de partido, posibilidades del legislador democrático, pero que al poder ser combatidas o rechazadas con idéntica legitimidad constitucional, el Estado no podría imponerlas como opciones éticas de obligada transmisión ${ }^{37}$.

Esto es debido a que, de acuerdo con Díez-Picazo, la educación es clave para lograr - al tiempo que defender - la autonomía individual que consagra la Constitución. En este sentido, podemos distinguir dos fines complementarios en el proceso educativo: facilitar el libre desarrollo de la personalidad (objetivo de carácter individual, enunciado en el propio art. 27.2 CE, con referencia al art. 10.1 CE) así como hacer posible la convivencia democrática (objetivo de carácter colectivo, subordinado al objetivo individual anteriormente reseñado), de manera que en opinión de este autor tanto del modelo de sociedad pluralista que diseña la Constitución en su art. 1 como del derecho reconocido en el art. 27.3 se deduce que una de las decisiones del constituyente es, precisamente, excluir la formación en valores morales de la competencia de los poderes públicos $^{38}$.

En la medida en que la CE 1978 no establece un sistema de «democracia militante», a juicio de Solozábal Echavarría la intervención estatal en el ámbito educativo dirigida a legitimar el propio Estado democrático y su orden constitucional debe referirse «exclusivamente a las manifestaciones institucionales de la democracia y a los supuestos ideológicos o sociales que la hacen posible» ${ }^{39}$.

Sentado lo anterior, debe ponerse de manifiesto que esta concepción restringida o mínima del ideario educativo constitucional no deja de ser problemática, en la medida en que pueden resaltarse serias divergencias doctrinales sobre elementos nucleares de la teoría del Estado constitucional.

Así, en primer lugar, y aun cuando se limitara el ideario educativo constitucional a la democracia, la transmisión del mismo debería afrontar cuestiones sobre cómo se concibe el pueblo que es titular de la soberanía. Como señala Böckenförde a propósito de la igualdad como elemento de la democracia, ésta «no entronca con la igualdad general entre los hombres, sino solo con la pertenencia a la comunidad política del pueblo», haciendo referencia a una cierta

37 FERNÁNDEZ-MIRANDA CAMPOAMOR, A. «Educación para la Ciudadanía. Una perspectiva constitucional», Educación en valores. Ideología y religión en la escuela pública, A. LÓPEZ CASTILLO (dir.), Centro de Estudios Políticos y Constitucionales, Madrid, 2007, pp. 152-153.

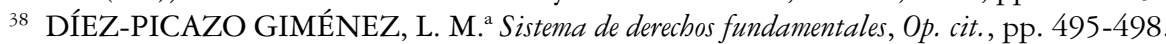

39 SOLOZÁBAL ECHAVARRÍA, J. J. «La enseñanza de valores, entre la libertad ideológica y el derecho a la educación», Educación en valores. Ideología y religión en la escuela pública, Op. cit., p. 146. 
homogeneidad prejurídica, homogeneidad que puede nacer por la existencia de una religión, una lengua o una cultura comunes (dando así origen a una concepción étnico cultural de la nación), o bien por compartir unas convicciones políticas comunes (dando origen, a su vez, a una concepción política de la nación, la «nación contrato» $)^{40}$.

Es decir, de un lado cabe defender un concepto de pueblo (de demos titular de la soberanía) en sentido liberal individualista, en que lo básico es conseguir que quienes van a estar sujetos al ordenamiento participen activamente en la creación del mismo; en esta concepción se asume una concepción racionalista del cuerpo político, según la cual éste nace de las nomas que lo organizan y regulan, sin que sea necesaria la existencia de un núcleo de tradiciones, valores o creencias de carácter prepolítico. Asumiendo esta concepción de pueblo, lo que debe hacer el legislador es «dotar de contenido personal a un sujeto colectivo, creado por el texto constitucional» ${ }^{41}$.

De otro lado, puede considerarse el pueblo como el «conjunto de hombres que, como unidad política de acción, forman parte del Estado y lo sostienen ${ }^{42}$, en la medida en que tienen «conciencia de su singularidad política y la voluntad de su existencia política» ${ }^{43}$, configurándose como «la asociación de los nacionales jurídicamente organizada y con capacidad de obrar» ${ }^{44}$. Lo relevante, desde esta perspectiva, es la pertenencia a la nación, «entendida como la unidad de voluntad orientada hacia la convivencia estatal, vinculada con características compartidas reales y contingentes tales como el origen, la religión, el idioma» ${ }^{45}$.

Como puede apreciarse, se trata de concepciones profundamente divergentes acerca de quién es el titular de la soberanía, divergencia que por ello se extiende

40 BÖCKENFÖRDE, E-W. «La democracia como principio constitucional», en Estudios sobre el Estado de Derecho y la democracia, Trotta, Madrid, 2000, pp. 87 y 88.

41 ALÁEZ CORRAL, B. «Nacionalidad, ciudadanía y democracia en la configuración de la nación/pueblo», Fundamentos. Cuadernos monográficos de Teoría del Estado, Derecho Público e Historia Constitucional, núm. 7, 2012, p. 119. Aun cuando Aláez Corral se está refiriendo a la legislación en materia de nacionalidad y su vinculación a la idea de ciudadanía, en mi opinión no se fuerza el argumento sostenido por este autor relacionándolo con el propósito de la educación.

42 BÖCKENFÖRDE, E-W. «La democracia como principio constitucional», Op. cit., p. 67.

43 SCHMITT, C. Teoría de la Constitución, Alianza Universidad, Madrid, 1992, p. 96.

${ }_{44}$ ISENSEE, J. «El pueblo fundamento de la Constitución», Anuario de Derechos Humanos, Nueva Época, Vol. 6, 2005, p. 448.

45 ISENSEE, J. «Solidaridad: el núcleo ético-social de un concepto impreciso», en Panorama de Filosofía Política. Contribuciones alemanas, OTFRIED HÖFFFE y JOSEF ISENSEE (compiladores), Konrad Adenauer Stiftung, Tubinga Bonn, 2002, p. 418. 
a qué debe entenderse por democracia, de manera que la reducción del ideario educativo constitucional —objeto de transmisión por medio de la educación-a la democracia sigue planteando dificultades desde la perspectiva de la neutralidad ideológica.

En efecto, la formación de ciudadanos desde la perspectiva del demos como objeto de construcción por el legislador (concepción racionalista del cuerpo político) conduce a una educación ciudadana en la que se transmitan los valores propios de la democracia pluralista pero sin que dicha transmisión implique una incorporación cultural a la nación. En cambio, si se admite que la democracia requiere de un demos previo a la acción del poder (y por tanto configurado por una cierta homogeneidad prejurídica que remite a la historia, la cultura o la etnia) la formación del ciudadano en los valores democráticos incluirá, además, alguna referencia a los presupuestos histórico-culturales que han permitido el nacimiento de la democracia en el mundo occidental.

Planteada esta disyuntiva, a mi modo de ver no se puede concluir que el problema de la neutralidad queda zanjado con la referencia a que la formación en el ideario democrático es una restricción de la libertad indispensable «para el ejercicio de la libertad y fomentar después la autonomía», como presunto corolario de la preponderancia del elemento democrático-participativo en la educación, a partir de la afirmación de que la Constitución «educa para la democracia y para el pluralismo en un contexto de pluralismo» ${ }^{46}$.

Tampoco se puede sostener, en mi opinión, una interpretación tan amplia del ideario educativo constitucional como la que propone Aláez Corral, para quien el mismo actúa como regla y como principio; como regla, dejando sin protección constitucional aquellas acciones educativas que conlleven una «desviación de las finalidades constitucionales a las que debe responder la educación» y como principio incluyendo un mandato de optimización del contenido del art. 27.2 CE que lleva a convertir el ideario educativo constitucional en límite interno de todos los derechos educativos ${ }^{47}$.

En el ámbito de la educación cívica, dirigida a fomentar la participación activa de los ciudadanos en el proceso democrático, la información susceptible de ser transmitida de modo objetivo, en mi opinión, podría consistir, como

46 ÁLVAREZ ÁLVAREZ, L. «La educación en el Estado social y democrático de derecho. El ideario educativo en la Constitución Española», en Los derechos sociales como instrumento de emancipación, M. A. PRESNO LINERA e I. WOLFGANG SARLET (editores), Thomson Reuters, Madrid, 2010, pp. 177 a 187.

47 ALÁEZ CORRAL, B. «El ideario educativo constitucional como límite a las libertades educativas», Op. cit., pp. 106 y ss. 
mucho, en la organización política adoptada por el Estado Español en la Constitución de 1978, lo que Ana María Redondo ha llamado «el modelo político convivencial» ${ }^{48}$, así como los derechos fundamentales reconocidos en la misma y en los Tratados Internacionales sobre la materia ratificados por España. Con otras palabras, la educación cívica debería consistir, a lo sumo, en la transmisión objetiva de conocimientos cuando tenga por objeto la enseñanza de aquello que sea corolario indispensable de la Constitución.

$Y$ es que una configuración más amplia del ideario educativo constitucional lleva a trasladar la competencia de formación cívica al legislador de cada momento. Así lo reconoce, por ejemplo, el propio Aláez Corral. Precisamente porque la educación cívica requiere del adoctrinamiento en valores y principios constitucionales que por su propia naturaleza tienen carácter abstracto, debe procederse a una mediación en el ámbito educativo para poder concretarlos en valores y principios susceptibles de formar la conciencia e informar el comportamiento de los futuros ciudadanos. Esta mediación necesaria para la comprensión de los valores y principios constitucionales debe realizarla el supremo intérprete de la Constitución (de manera que la jurisprudencia del TC no sólo vincularía a jueces y Tribunales ex art. 5 LOPJ, sino que se erigiría en canon de enjuiciamiento de los contenidos educativos), pero también el propio legislador «que es llamado expresamente por el texto constitucional (artículos 53.1 y 81) a desarrollar (concretar) el sentido de las disposiciones sobre derechos fundamentales y, con ello, del libre desarrollo de la personalidad ${ }^{49}$. Con otras palabras, que los valores y principios constitucionales que pueden imponerse en la educación tienen un contenido abierto, que debe ser concretado por el legislador ${ }^{50}$.

48 REDONDO, A. M. Defensa de la Constitución y enseñanza básica obligatoria (integración educativa intercultural y homeschooling), Tirant lo Blanch, Valencia, 2003, p. 105.

49 ALÁEZ CORRAL, B. «El ideario educativo constitucional como límite a las libertades educativas», Op. cit., p. 113.

50 De manera coherente con este planteamiento — pero no por ello menos llamativa- este autor llega a preguntarse si acaso el mandato derivado del ideario educativo constitucional debería vincular «incluso a la educación que tenga lugar fuera del sistema educativo reglado, como la que desarrollan las familias en sus casas», ALÁEZ CORRAL, B. «El ideario educativo constitucional como límite a las libertades educativas», p. 106, nota 28. Ahora bien, aparte de las dificultades anejas a la cuestión de cómo hacer cumplir esta pretensión (¿dónde quedaría el derecho a la intimidad o la inviolabilidad del domicilio?), me parece claramente excesivo extender la competencia del legislador hasta el punto de poder condicionar lo que los padres quieran transmitir a sus hijos, libremente, en sus casas. 


\section{LA CUESTIÓN DE LA LEGITIMIDAD DE LOS COLEGIOS ESPECIALIZADOS POR RAZÓN DE SEXO}

En los últimos tiempos, al hilo de decisiones de algunas administraciones educativas autonómicas dirigidas a retirar —o no renovar- el concierto a centros docentes de iniciativa social que siguen el modelo de la educación diferenciada $^{51}$, se ha planteado la cuestión de si en aplicación del ideario educativo constitucional deben excluirse este tipo de centros, ya sea de la financiación pública, ya sea incluso del sistema educativo en general.

Ya en una Sentencia de 20 de diciembre de 1999, la Audiencia Nacional consideró que

«El hecho de que en un centro docente se impartan enseñanzas sólo a niños o sólo a niñas no puede considerarse que suponga una discriminación por razón de sexo, desde el momento en que los padres o tutores pueden elegir, dentro de un entorno gratuito de enseñanza, entre los diversos centros existentes en un determinado territorio.»

Por su parte, la Sentencia del Tribunal Superior de Justicia de La Rioja, de fecha 25 de noviembre de 2002 (Ar. 2003/72831) señaló al respecto que

«El hecho de que un centro educativo escolarice sólo niñas o sólo niños en absoluto permite deducir que se trate de discriminación por razón de sexo contraria a Derecho. En un Estado de Derecho en que se reconoce la libertad de enseñanza —artículo 27.1 de la Constitución — y el derecho de los padres para que sus hijos reciban la educación religiosa y moral que esté de acuerdo con sus convicciones - art. 27.3 de la Constitución - y la libertad de creación de centros docentes — art. 27.5—, así como la libertad de empresa —art. 38-, no puede pretenderse la uniformidad propugnada por la parte actora como único modelo educativo legítimo» (FJ 4).

El Tribunal Supremo, en cambio, no ha vinculado la educación diferenciada con un modelo educativo (por tanto con fundamento pedagógico, lo que podría tener entonces una protección constitucional en el ideario o carácter propio del centro, que de acuerdo con la STC 5/1981 no tiene que entenderse limitado a

51 La educación diferenciada consiste en separar a los niños por sexo, al menos en determinadas etapas educativas. Puede hacerse diferenciando a los centros escolares, especializando los colegios en función del sexo de los alumnos, o bien separando a los niños y a las niñas en aulas diferentes dentro de un mismo centro. Quienes defienden esta opción pedagógica justifican el modelo los diferentes ritmos de maduración de chicos y chicas, considerando que la calidad y la eficacia de la educación obligan a atender a las necesidades de cada alumno y su diversidad, y muy especialmente el distinto modo de aprender de alumnas y alumnos. Cfr. «Qué es educación diferenciada», Boletín de OIDEL, núm. 10, enero 2006, p. 2. 
las cuestiones morales o religiosas), sino con los criterios de admisión de alumnos establecidos por los titulares de los centros. De ahí que no considere el establecimiento de este modelo pedagógico derivación necesaria del art. 27, sino un derecho de configuración legal ${ }^{52}$.

En efecto, ya en una Sentencia de 11 de junio de $2008^{53}$, el Tribunal Supremo manifestó que

«Ni la LODE ni la LOCE reconocen a los titulares de los centros concertados el derecho a establecer en ellos un sistema de enseñanza diferenciada como parte integrante de su derecho de creación y dirección de centros privados y que, por esta razón, deba ser aceptado como un contenido adicional de lo directamente establecido en el artículo $27 \mathrm{CE}$.

Consiguientemente, carece de fundamento esa vulneración a la configuración legal del derecho fundamental reconocido en dicho artículo 27 CE que la sentencia recurrida viene a atribuir a las normas reglamentarias impugnadas por esa mención del «sexo» contenida en ellas que anula.

El sistema de enseñanza mixta, en el caso de los centros concertados, es una manifestación o faceta más de esa competencia sobre la admisión del alumnado que corresponde a la Administración educativa que financia dichos centros concertados; esto es, forma parte de esa intervención estatal que limita el derecho de dirección en los centros privados que reciben ayudas públicas en virtud de lo establecido en el artículo 27.9 CE» (FJ 9).

En sentido similar se expresa el Tribunal Supremo en su Sentencia de 23 de julio de $2012^{54}$, al interpretar que lo señalado en la Disposición Adicional Vigésimo quinta de la LOE conforme a la cual los centros que apliquen el modelo de coeducación «"serán objeto de atención preferente y prioritaria en la aplicación de las previsiones recogidas en la presente Ley", no excluye la existencia en el sistema educativo español de otros centros docentes que no sigan ese modelo», si bien del tenor de la LOE se desprende que aun cuando en la LOE «se reconoce la legitimidad del sistema docente de educación diferenciada por sexos, se

52 Esto ha sido criticado por González-Varas Ibáñez, quien sostiene que se trata de una manifestación de la libertad de enseñanza en su vertiente de derecho a la libre creación de centros docentes. Cfr. GONZÁLEZ-VARAS IBÁÑEZ, A. «Régimen jurídico de la educación diferenciada en España», Revista General de Derecho Canónico y Derecho Eclesiástico del Estado, núm. 31, 2013, p. 14.

53 Sentencia del Tribunal Supremo de 11 de junio de 2008, dictada con ocasión del Recurso de Casación núm. 689/2005 (Ponente: Excmo. Sr. José Díaz Delgado).

${ }^{54}$ Sentencia del Tribunal Supremo de 23 de julio de 2012, dictada con ocasión del Recurso de Casación núm. 4591/2011 (Ponente: Excmo. Sr. Santiago Martínez-Vares García). 
excluye a esos centros de la posibilidad de concertar con la Administración competente su sostenimiento con fondos públicos» $(\mathrm{FJ} 3)^{55}$.

Esta doctrina ha sido reiterada por el Tribunal Supremo en sus Sentencias de $14^{56}$ y $15^{57}$ de enero de 2013, que de nuevo vincula el modelo de educación diferenciada con los criterios de admisión de alumnos que pueda establecer el titular del centro en lugar de con el ideario o carácter propio que al mismo pueda establecer.

En cualquier caso, y dejando en función del objeto de este trabajo la cuestión de la financiación pública de los centros que aplican este modelo pedagógico, parece claro que la educación diferenciada no vulnera el ideario educativo constitucional, por no implicar, per se, una educación discriminatoria ${ }^{58}$.

55 Esta argumentación del Tribunal Supremo ha sido criticada por José Luis Martínez LópezMuñiz. Así, considera que dicha argumentación mina «los fundamentos mismos del Estado de Derecho», en la medida en que implica considerar que únicamente es merecedora de protección jurídica la libertad expresamente incluida por el legislador en la norma, a pesar de que «los componentes del derecho a la educación como derecho de libertad no desaparecen ni se aminoran con la exigibilidad prestacional propia del derecho a la educación como derecho social». MARTÍNEZ LÓPEZ-MUÑIZ, J. L. «Escolarización homogénea por razón del sexo y derecho fundamental a la educación en libertad», Revista Española de Derecho Administrativo, núm. 154, 2012, pp. 101 y 105.

56 Sentencia del Tribunal Supremo de 15 de enero de 2013, dictada con ocasión del Recurso de Casación núm. 1303/2012 (Ponente: Excma. Sra. Celsa Pico Lorenzo).

57 Sentencia del Tribunal Supremo de 15 de enero de 2013, dictada con ocasión del Recurso de Casación núm. 4928/2011 (Ponente: Excmo. Sr. Enrique Lecumberri Martí).

${ }^{58}$ Cfr. GONZÁLEZ-VARAS IBÁÑEZ, A. «Régimen jurídico de la educación diferenciada en España», Revista General de Derecho Canónico y Derecho Eclesiástico del Estado, núm. 31, 2013, pp. 5 y ss. A semejantes conclusiones en relación con la redacción originaria del art. 84.3 de la LOE («En ningún caso habrá discriminación por razón de nacimiento, raza, sexo, religión, opinión o cualquier otra condición o circunstancia personal o social») llega Martínez López-Muñiz, con un extenso análisis sobre la génesis del mencionado precepto; en este sentido, cfr. MARTÍNEZ LÓPEZ-MUÑIZ, J. L. «Los conciertos con colegios de un solo sexo en la Ley de Presupuestos Generales del Estado», Diario La Ley, 330/2013, 25 de febrero de 2013. Este precepto ha sido modificado por el apartado Sesenta y uno del artículo único de la Ley Orgánica 8/2013, de 9 de diciembre, para la mejora de la calidad educativa, conforme al cual la nueva redacción de dicho art. 84.3 es la siguiente:

«En ningún caso habrá discriminación por razón de nacimiento, raza, sexo, religión, opinión o cualquier otra condición o circunstancia personal o social.

No constituye discriminación la admisión de alumnos y alumnas o la organización de la enseñanza diferenciadas por sexos, siempre que la enseñanza que impartan se desarrolle conforme a lo dispuesto en el artículo 2 de la Convención relativa a la lucha contra las discriminaciones en la esfera de la enseñanza, aprobada por la Conferencia General de la UNESCO el 14 de diciembre de 1960.

En ningún caso la elección de la educación diferenciada por sexos podrá implicar para las familias, alumnos y alumnas y centros correspondientes un trato menos favorable, ni una desventaja, a la hora de suscribir conciertos con las Administraciones educativas o en cualquier otro 
Como señala Martínez López-Muñiz,

«no cabe estimar discriminación por razón de sexo en la educación la creación y mantenimiento de centros escolares separados para alumnos sólo del sexo masculino o sólo del sexo femenino, como mejor modo pedagógico de adaptar y ajustar la tarea educativa a las especificidades de uno y otro y a su diverso ritmo de crecimiento y maduración, insertándola en dinámicas de grupo más efectivas. Con la única condición de que los centros así diferenciados se atengan a igualdad de requisitos de programa y de exigencias de objetivos y rendimiento al alumnado, cualificación del profesorado y calidad de medios materiales, permitiendo al sistema escolar que todas las personas en edad escolar de uno y otro sexo puedan alcanzar los mismos niveles educativos y las mismas especialidades, sin perjuicio de las diferencias que en punto a la accesibilidad efectiva a las correspondientes enseñanzas presente el sistema — para todos—, según se trate de enseñanzas obligatorias (en España, la primaria y la secundaria obligatoria) o facultativas (en España todas las demás)» ${ }^{59}$.

Para Aláez Corral, la cuestión no debe centrarse en la existencia o no de discriminación, sino «en saber si una pedagogía como la que propone la educación diferenciada, basada en la organización general o parcial de la enseñanza a partir de las diferencias derivadas del sexo, conlleva una garantía del derecho a la educación conforme al ideario constitucional» ${ }^{60}$. Dicho esto, y partiendo de que corresponde al legislador orgánico la delimitación del contenido del derecho a la educación, concluye que a la vista de la regulación legal sobre esta materia (arts. 2.b LODE y 2.b LOE, que incluyen dentro de los fines educativos la formación en la igualdad entre hombres y mujeres) la educación diferenciada queda «bajo la sospecha de ser disfuncional para lograr una educación» conforme con las finalidades constitucionales, lo cual le lleva a considerar la posible inconstitucionalidad de la educación diferenciada, pues «pone en peligro la garantía del derecho a la educación conforme al ideario educativo» ${ }^{61}$. Ahora bien, dado que no ha sido expresamente prohibida por el legislador orgánico debe entenderse que es un

aspecto. A estos efectos, los centros deberán exponer en su proyecto educativo las razones educativas de la elección de dicho sistema, así como las medidas académicas que desarrollan para favorecer la igualdad.»

59 MARTÍNEZ LÓPEZ-MUÑIZ, J. L. «Siete tesis sobre la legalidad de una educación escolar especializada por razón de sexo», en J. M. ${ }^{a}$ BARRIO (dir.), Educación diferenciada, una opción razonable, EUNSA, Pamplona, 2005. pp. 214-215.

60 ALÁEZ CORRAL, B. «El ideario educativo constitucional como fundamento de la exclusión de la educación diferenciada por razón de sexo de la financiación pública», Revista Española de Derecho Constitucional, núm. 86, 2009, p. 42.

${ }^{61}$ ALÁEZ CORRAL, B. «El ideario educativo constitucional como límite a las libertades educativas», Op. cit., p. 122. 
modelo pedagógico al que pueden acogerse los centros privados, pero por las razones apuntadas es lícito que el legislador, en virtud de su política de derechos fundamentales, excluya a estos centros de la financiación pública ${ }^{62}$.

En relación con la educación diferenciada y su incapacidad de garantizar adecuadamente el ideario educativo constitucional, este autor deriva —en primer término- de la previsión del art. 27.2 CE de que la educación debe realizarse «en el respeto a los principios democráticos de convivencia y a los derechos y libertades fundamentales», una obligación de hacer efectiva la igualdad de género en la educación ${ }^{63}$. De esta obligación, en segundo lugar deriva que esta igualdad no debe proyectarse únicamente en el ámbito de la transmisión de conocimientos ${ }^{64}$, sino que debe hacerlo también en la formación en valores, requiriendo incluso la interiorización de esta igualdad. Y, en tercer término, de esta obligación de interiorizar la igualdad de género, concluye que se trata de un proceso que únicamente puede realizarse en un contexto de coeducación, por medio de la convivencia en las aulas de alumnos de los dos sexos.

A mi entender, en la argumentación de Aláez Corral hay, de nuevo, una interpretación demasiado extensiva del ideario educativo constitucional. A la luz de la jurisprudencia constitucional, no plantea problema alguno el primer paso en su argumentación; así, es posible convenir que a la luz del art. 27.2 CE la educación deba servir para hacer efectiva la igualdad entre hombres y mujeres, lo cual además no sería sino proyección en el ámbito educativo de la cláusula de igual dignidad del art. 10 CE y del principio de igualdad del art. 14 CE. Asimismo, puede conectarse el segundo paso de su argumentación (la igualdad como valor que debe ser interiorizado en el proceso de enseñanza) con la jurisprudencia del Tribunal Supremo dictada en relación con la objeción de conciencia a las asignaturas englobadas en la materia de Educación para la Ciudadanía. Sin embargo, a mi juicio hay un salto en el tercer paso de su argumentación que no encuentra apoyo ni en la Constitución ni en la jurisprudencia (del TC o del TS).

62 ALÁEZ CORRAL, B. «El ideario educativo constitucional como fundamento de la exclusión de la educación diferenciada por razón de sexo de la financiación pública», Op. cit., pp. 49-52.

63 Así, de conformidad con el art. 2.1.b de la Ley orgánica 2/2006, de 3 de mayo, de Educación uno de los fines del proceso educativo es «La educación en el respeto de los derechos y libertades fundamentales, en la igualdad de derechos y oportunidades entre hombres y mujeres y en la igualdad de trato y no discriminación de las personas con discapacidad».

${ }^{64}$ A esto parece referirse el art. 2.a de la Convención de la UNESCO de 14 de diciembre de 1960 para la Lucha contra las discriminaciones en la esfera de la enseñanza, conforme al cual no se considerará discriminación «La creación o el mantenimiento de sistemas o establecimientos de enseñanza separados para los alumnos de sexo masculino y para los de sexo femenino, siempre que esos sistemas o establecimientos ofrezcan facilidades equivalentes de acceso a la enseñanza, dispongan de un personal docente igualmente calificado, así como de locales escolares y de un equipo de igual calidad y permitan seguir los mismos programas de estudio o programas equivalentes». 
En efecto, en materia educativa — también en la interiorización de valores constitucionales- nos encontramos ante una obligación de resultado ${ }^{65}$, sin que en una sociedad pluralista pueda imponerse un único modo de alcanzar los objetivos o fines establecidos por el legislador para la educación.

No hay duda de que el modelo de educación diferenciada permite alcanzar los objetivos pedagógicos establecidos por el legislador. Pero es que, además, se trata de un modelo pedagógico que permite alcanzar los fines adicionales que se pueden hacer derivar del art. 27.2 CE (la competencia social y ciudadana, la interiorización de la igualdad entre hombres y mujeres). De no ser así, los centros docentes de educación diferenciada no tendrían que ser excluidos del sistema de conciertos, sino que deberían ser excluidos del sistema educativo. Pero como tuvo ocasión de señalar el Tribunal Supremo en su Sentencia de 23 de julio de 2012, la educación diferenciada es «tan legítima como el modelo de coeducación que preconiza la Ley» (FJ 3), legitimidad que no podría predicarse si dicho modelo no fuera apto para alcanzar los objetivos y fines de la educación previstos por la Constitución o la legislación educativa.

$\mathrm{Y}$ es que, como ha señalado Esteve Pardo, «la coeducación no está en el ideario constitucional, ni puede estarlo porque no es un objetivo educativo, ni un valor o fin en sí mismo». La educación conjunta de varones y mujeres se presenta así como un «medio instrumental» al servicio de «alcanzar los objetivos de enseñanza y formación humana» establecidos por el ordenamiento. Pero si es un medio instrumental y no un fin, debe predicarse la necesaria «neutralidad de los poderes públicos en las libres opciones por modelos legítimos» ${ }^{66}$.

De manera que afirmar que los centros de educación diferenciada no cumplen con el ideario educativo constitucional implica considerar que hay una sola manera de entender y alcanzar la igualdad entre hombres y mujeres, o que esta igualdad tiene un contenido fijo, determinado por el legislador. Pero esta conclusión, a mi entender, no es compatible con el pluralismo que garantiza la propia Constitución, pues supone que debe ser universalizable el medio por el que opta —entre todos los posibles - el legislador para alcanzar fines constitucionales.

Como señalan Fernández-Miranda y Sánchez Navarro, «la realidad de una sociedad pluralista muestra que no hay ciudadanos distintos porque haya escuelas diferentes, sino cabalmente todo lo contrario: hay escuelas distintas y partidos políticos distintos, y medios de comunicación distintos... porque hay ciudadanos

${ }^{65}$ Cfr. DÍEZ-PICAZO, L. M. ${ }^{a}$ Sistema de derechos fundamentales, Op. cit., pp. 500-501.

${ }^{66}$ ESTEVE PARDO, J. «Paradojas de la discriminación en materia educativa. A propósito de la Sentencia del Tribunal Supremo Federal Alemán de 30 de enero de 2013 sobre el modelo de educación diferenciada», El cronista del Estado social y democrático de Derecho, núm. 37, 2013, p. 11. 
con diversas percepciones de la existencia» ${ }^{67}$. Pretender que ciudadanos con diversas percepciones sobre el modo de alcanzar e interiorizar la igualdad entre hombres y mujeres deban asumir la definida por el legislador (es decir, por la mayoría política de turno) significa, a mi entender, que la formación de los ciudadanos excedería de la asunción del marco constitucional para imponer una concreta opción dentro de dicho marco ${ }^{68}$.

\section{CONCLUSIONES}

A partir de las consideraciones precedentes podemos concluir en que el art. 27.2 CE establece un verdadero ideario educativo constitucional, al asignar a la educación no sólo la transmisión de conocimientos, sino también la formación en los principios y valores constitucionales requeridos para el ejercicio de una ciudadanía activa y participativa. En definitiva, se trata capacitar a los alumnos para el ejercicio de la libertad, también en la vida social.

Ahora bien, precisamente por ello y para evitar el riesgo del dirigismo cultural, este ideario educativo constitucional debe interpretarse de manera restrictiva. $\mathrm{Y}$ es que, así como hemos señalado que este ideario ha sido perfilado y delimitado por la jurisprudencia en procesos de protección de derechos fundamentales, también el contenido del mismo debe entenderse limitado y restringido precisamente para respetar derechos fundamentales.

La razón es, a mi entender, sencilla: siendo relativamente pacífica y generadora de consenso la exposición de la parte orgánica de la Constitución, no sucede lo mismo con la parte dogmática de la misma. En efecto, en la parte dogmática de la Constitución encontramos una cierta tensión entre libertad e igualdad, por lo que la explicación de estos valores (como los complementarios de justicia y pluralismo político) no deja de ser problemática, presentando el riesgo de una politización total de los alumnos.

Este riesgo, con su potencial adoctrinador (recordemos que el Tribunal Supremo ha aceptado que es lícito que el legislador intente no sólo el conocimiento, sino la adhesión a dichos principios), no deja de existir aun cuando se limitara únicamente a normas de derecho positivo. En primer lugar, porque puede haber normas de derecho positivo que reconocen valores, principios y

${ }^{67}$ FERNÁNDEZ-MIRANDA CAMPOAMOR, A. y SÁNCHEZ NAVARRO, A. «Artículo 27: Enseñanza», en Comentarios a la Constitución Española de 1978, O. ALZAGA (dir.), Tomo III, EDERSA Cortes Generales, Madrid, 1996, p. 184.

${ }^{68}$ NUEVO LÓPEZ, P. «La introducción de la asignatura "Educación para la Ciudadanía” y la concepción constitucional del pluralismo político», Op. cit., p. 77. 
derechos sobre los que subsista un notable grado de discrepancia en la sociedad. Es el caso, a título de ejemplo, con los contenidos en algunos Estatutos de Autonomía, como son los de Cataluña y Andalucía, pues siendo la educación una materia sobre la que han asumido competencias las Comunidades Autónomas parece que éstas puedan tener un interés en concretar, en relación con su respectiva Norma institucional básica, la proyección del ideario educativo constitucional a escala autonómica ${ }^{69}$.

Pero, en segundo lugar, porque en relación con determinados derechos fundamentales reconocidos en el Texto constitucional de 1978 (a modo de ejemplo, el derecho a la vida, el derecho a la autonomía personal, el derecho a la libertad religiosa y de conciencia o el siempre delicado ámbito de las proyecciones de la igualdad en las relaciones entre particulares) no es pacífica la cuestión del contenido y alcance de los mismos. Extender en exceso el contenido del ideario educativo constitucional puede implicar querer convertir lo legal en criterio de moralidad y en parámetro para enjuiciar el ejercicio de los derechos de libertad (por ejemplo, el derecho de los padres a elegir la educación moral y religiosa de sus hijos).

Una interpretación amplia del ideario educativo constitucional abriría la puerta a un desdibujamiento de la distinción entre Estado y Sociedad, elemento clave de la protección de la libertad en el Estado constitucional.

Como señala Böckenförde, la libertad política de participación de todos en el poder del Estado que asegura el Estado democrático tiene lugar junto a la libertad civil de los individuos y la sociedad, que protege contra ciertas intervenciones del poder estatal. En este sentido «abandonar la limitación funcional del Estado invocando el carácter democrático del poder de decisión estatal conlleva reducir la libertad a mera participación democrática», con la consecuencia de que «si se considera que el Estado tiene una competencia ilimitada por disponer de legitimación democrática, el poder de decisión estatal sobre el indivi-

${ }^{69}$ En este sentido, el Decreto de la Generalidad de Cataluña 143/2007, de 26 de junio, por el que se establece la ordenación de las enseñanzas de la educación secundaria obligatoria (DOGC núm. 4915, de 29 de junio) establece expresamente que se prestará especial atención a los derechos estatutarios. En similar sentido se expresa el Decreto del Gobierno de Andalucía 231/2007, de 31 de julio, por el que se establece la ordenación y las enseñanzas correspondientes a la educación secundaria obligatoria en Andalucía (BOJA núm. 156, de 8 de agosto), que establece que en Educación Secundaria Obligatoria el currículo incluirá la formación en los valores estatutarios. Pero a la vista de las nuevas regulaciones estatutarias en materia de derechos y libertades (así, por ejemplo, el Título I del nuevo Estatuto de Autonomía para Cataluña, aprobado mediante la Ley orgánica 6/2006, de 19 de julio, o el Título I del nuevo Estatuto de Autonomía para Andalucía, aprobado por Ley orgánica 2/2007, de 19 de marzo), la transmisión en el sistema reglado de enseñanza de los derechos, principios y valores presentes en estas normas conlleva, de suyo, un abandono de la neutralidad. 
duo y la sociedad deviene total. En esta perspectiva, democracia significa que todos pueden decidir sobre todo. Sólo existe, en consecuencia, libertad de participación en el proceso democrático, pero no libertad ante dicho proceso. El resultado es la democracia total, en la que el individuo es en todas sus dimensiones miembro de la colectividad democrática, tomando aquella necesariamente un carácter totalitario» ${ }^{70}$.

\section{BIBLIOGRAFÍA}

ALÁEZ CORRAL, B., «El ideario educativo constitucional como límite a las libertades educativas», Revista Europea de Derechos Fundamentales, núm. 17, 2011.

- «El ideario educativo constitucional como fundamento de la exclusión de la educación diferenciada por razón de sexo de la financiación pública», Revista Española de Derecho Constitucional, núm. 86, 2009.

- «Ideario educativo constitucional y respeto a las convicciones morales de los padres: a propósito de las sentencias del Tribunal Supremo sobre "Educación para la ciudadanía” ", El Cronista del Estado Social y Democrático de Derecho, núm. 5, 2009.

- «Caso Folgero y respeto a las convicciones morales de los padres en materia educativa», Repertorio Aranzadi del Tribunal Constitucional, núm. 3, 2008.

- «El derecho a la educación del menor como marco delimitador de los criterios de admisión a los centros escolares sostenidos con fondos públicos», en VV. AA., Escolarización del alumnado en el sistema educativo español: cuestiones jurídicas, Fundación Europea Sociedad y Educación, Madrid, 2006.

ÁLVAREZ ÁLVAREZ, L., «La educación en el Estado social y democrático de derecho. El ideario educativo en la Constitución Española», en Los derechos sociales como instrumento de emancipación, M. A. PRESNO LINERA e I. WOLFGANG SARLET (editores), Thomson Reuters, Madrid, 2010.

BARNÉS, J., «La educación en la Constitución. Una reflexión conciliadora», Revista Española de Derecho Constitucional, núm. 12, 1984.

BARRIO MAESTRE, J. M., «Educación para los derechos humanos», Hacia una cultura de los derechos bumanos. Universidad de Verano de derechos bumanos y del derecho a la educación, FERNÁNDEZ, A. (ed.), Ginebra, 2000.

BÖCKENFÖRDE, E. W., «La signification de la distinction entre État et société pour l'État social et démocratique contemporain", Le droit, l"État et la constitution démocratique, Bruylant LGDJ, Paris, 2000.

${ }^{70}$ BÖCKENFÖRDE, E. W. « La signification de la distinction entre État et société pour l'État social et démocratique contemporain ", Le droit, l'État et la constitution démocratique, Bruylant LGDJ, Paris, 2000, pp. 188 y 189. 
CÁMARA VILLAR, G., «Constitución y Educación (los derechos y libertades del ámbito educativo a los veinte años de vigencia de la Constitución Española de 1978), La experiencia constitucional, 1978-2000, Centro de Estudios Políticos y Constitucionales, Madrid, 2000.

- «Sobre el concepto y los fines de la educación en la Constitución Española», Introducción a los derechos fundamentales: X Jornadas de Estudio, Ministerio de Justicia, Madrid, Vol. III, 1989.

DÍEZ-PICAZO GIMÉNEZ, L. M. a, Sistema de derechos fundamentales, 3.a ed., Civitas, Madrid, 2008.

EMBID IRUJO, A., «Educar a ciudadanos. Reflexiones en torno a las Sentencias del Tribunal Supremo de 11 de febrero de 2009 sobre la "Educación para la ciudadanía”», El Cronista del Estado social y democrático de derecho, núm. 4, 2009.

- «La educación para la ciudadanía en el sistema educativo español. Reflexiones jurídicas», Revista Española de Derecho Constitucional, núm. 83, 2008.

ESTEVE PARDO, J., «Paradojas de la discriminación en materia educativa. A propósito de la Sentencia del Tribunal Supremo Federal Alemán de 30 de enero de 2013 sobre el modelo de educación diferenciada», El cronista del Estado social y democrático de Derecho, núm. 37, 2013.

FERNÁNDEZ-MIRANDA CAMPOAMOR, A., «Educación para la Ciudadanía. Una perspectiva constitucional», Educación en valores. Ideología y religión en la escuela pública, A. LÓPEZ CASTILLO (dir.), Centro de Estudios Políticos y Constitucionales, Madrid, 2007.

FERNÁNDEZ-MIRANDA CAMPOAMOR, A. y SÁNCHEZ NAVARRO, A., «Artículo 27: Enseñanza», en Comentarios a la Constitución Española de 1978, O. ALZAGA (dir.), Tomo III, EDERSA Cortes Generales, Madrid, 1996.

FERNÁNDEZ-MIRANDA CAMPOAMOR, A., De la libertad de enseñanza al derecho a la educación. Los derechos educativos en la Constitución Española, Centro de Estudios Ramón Areces, Madrid, 1988.

GARRIDO FALLA, F., «La elaboración de la Constitución», en M. BALADO y J. A. REGUEIRO (dirs.), La Constitución de 1978 en su XXV Aniversario, Bosch, Barcelona, 2003.

— «La salvaguardia de la identidad propia de las escuelas de la Iglesia», Constitución y Acuerdos Iglesia-Estado, Universidad Pontificia de Comillas, Madrid, 1988.

— «Artículo 27», en F. GARRIDO FALLA (dir.), Comentarios a la Constitución, Civitas, Madrid, 1985.

GÓMEZ ORFANEL, G., «Jurisprudencia española sobre educación para la ciudadanía», Anuario de Derechos Humanos (Nueva época), Vol. 10, 2009.

GONZÁLEZ, M. y NAVAL, C., «Una aproximación a la educación para la ciudadanía en Europa en la última década», La educación cívica hoy. Una perspectiva interdisciplinar, NAVAL, C. y LASPALAS, J. (eds.), EUNSA, Pamplona, 2000. 
GONZÁLEZ-VARAS IBÁÑEZ, A., «Régimen jurídico de la educación diferenciada en España», Revista General de Derecho Canónico y Derecho Eclesiástico del Estado, núm. 31, 2013

MARTÍ SÁNCHEZ, J. M. ', «El “bome schooling” en el Derecho español», Revista General de Derecho Canónico y Derecho Eclesiástico del Estado, núm. 25, 2011.

— «La Educación para la Ciudadanía: Ley Orgánica 2/2006, de Educación», Anuario de Derecho Eclesiástico del Estado, núm. 23, 2007.

— «Objeciones de conciencia y escuela», Revista General de Derecho Canónico y Derecho Eclesiástico del Estado, núm. 15, 2007.

- «La educación para la ciudadanía en el sistema de la Ley Orgánica de Educación (Una reflexión desde la libertad religiosa)», Revista General de Derecho Canónico y Derecho Eclesiástico del Estado, núm. 10, 2006.

MARTÍNEZ DE PISÓN, J., El derecho a la educación y la libertad de enseñanza, Dykinson, Madrid, 2006.

MARTÍNEZ LÓPEZ-MUÑIZ, J. L., «Los conciertos con colegios de un solo sexo en la Ley de Presupuestos Generales del Estado», Diario La Ley, 330/2013, 25 de febrero de 2013.

- «Escolarización homogénea por razón del sexo y derecho fundamental a la educación en libertad», Revista Española de Derecho Administrativo, núm. 154, 2012.

- «Siete tesis sobre la legalidad de una educación escolar especializada por razón de sexo», en J. M. BARRIO (dir.), Educación diferenciada, una opción razonable, EUNSA, Pamplona, 2005.

NUEVO LÓPEZ, P., La Constitución educativa del pluralismo. Una aproximación desde la teoría de los derechos fundamentales, NetBiblo-UNED, La Coruña, 2009.

- «La introducción de la asignatura "Educación para la Ciudadanía” y la concepción constitucional del pluralismo político», Cuadernos constitucionales de la Cátedra Fadrique Furió Ceriol, núm. 56, 2006.

PÉREZ ROYO, J., Curso de Derecho Constitucional, Marcial Pons, Madrid, 2000.

PRIETO SANCHÍS, L., «Las relaciones Iglesia-Estado a la luz de la nueva Constitución: problemas fundamentales», en A. PEDRIERI y E. GARCÍA DE ENTERRÍA (dirs.) La Constitución Española de 1978, Civitas, Madrid, 1981.

REDONDO, A. M., Defensa de la Constitución y enseñanza básica obligatoria (integración educativa intercultural y homeschooling), Tirant lo Blanch, Valencia, 2003.

RUBIO LLORENTE, F., «Los deberes constitucionales», Revista Española de Derecho Constitucional, núm. 62, 2001, p. 29.

RUANO ESPINA, L., «Las Sentencias del Tribunal Supremo de 11 febrero de 2009 sobre objeción de conciencia a EPC», Revista General de Derecho Canónico y Derecho Eclesiástico del Estado, núm. 20, 2009.

SÁNCHEZ FERRIZ, R., y JIMENA QUESADA, L., La enseñanza de los derechos bumanos, Ariel, Barcelona, 1995. 
SÁNCHEZ-AGESTA, L., Sistema político de la Constitución Española de 1978, Editora Nacional, 1981.

SOLOZÁBAL ECHAVARRÍA, J. J., «La enseñanza de valores, entre la libertad ideológica y el derecho a la educación», Educación en valores. Ideología y religión en la escuela pública, A. LÓPEZ CASTILLO (dir.), Centro de Estudios Políticos y Constitucionales, Madrid, 2007.

VALERO HEREDIA, A., «Ideario educativo constitucional y "homeschooling": a propósito de la Sentencia del Tribunal constitucional 133/2010, de 2 de diciembre», Revista Española de Derecho Constitucional, núm. 94, 2012.

Title:

FUNDAMENTAL RIGHTS AND THE EDUCATIONAL IDEOLOGY OF THE CONSTITUTION.

\section{Summary:}

I. The educational ideology of the Constitution. II. Compulsory schooling and purpose of education. III. The issue of education for citizenship and the educational ideology of the Constitution. IV. The question of the legitimacy of the schools specialized by gender. V. Conclusions.

\section{Resumen:}

La regulación de los derechos educativos ha demostrado ser una de las más conflictivas de la experiencia constitucional española. Si en la década de los 80 el conflicto giró alrededor de la articulación de la educación pública y la de iniciativa social (y la correspondiente financiación de este tipo de educación) y en los debates entre pluralismo interno y pluralismo externo en la enseñanza, en los últimos años ha emergido el disenso en torno a qué debe entender por educación. En este sentido, ha cobrado actualidad el debate en torno al ideario educativo constitucional.

En el presente artículo se examina la existencia del ideario educativo constitucional y el alcance del mismo, a partir de su proyección en la resolución de conflictos jurídicos que en esta materia han tenido lugar en los últimos años.

Así, en primer lugar se analiza la cuestión de la educación en casa, y su interrelación con el mencionado ideario educativo constitucional, al objeto de determinar cuál es la finalidad de la educación.

En segundo término, y dado que el Tribunal Constitucional considera que la educación tiene una finalidad de integración social que va más allá de la transmisión de conocimientos, se analiza esta vertiente cívica de la educación, a partir de la polémica generada por la introducción en el currículo de la materia «Educación para la ciudadanía». 
En tercer lugar, y en atención a la relación entre ideología constitucional y enseñanza institucional, se considera la legitimidad de los colegios especializados por sexo.

Finalmente, a partir de las consideraciones efectuadas en los casos citados, se propone una concepción restrictiva del ideario educativo constitucional, en orden a preservar el pluralismo político y la distinción entre Estado y sociedad, clave en una sociedad democrática.

\section{Abstract:}

The regulation of the educational rights has proven to be one of the most troubled of the Spanish constitutional experience. If in the 80s the conflict revolved around the articulation of public education and social initiative (and funding of such education) and discussions between internal and external pluralism in education, in recent years has emerged dissent about what is meant by education. In this sense, the debate has gained currency in the constitutional educational ideology.

In this paper is examined the existence and scope of the educational ideology of the Constitution, from its projection in the resolution of legal disputes in this area that have taken place in recent years.

Firstly, is analyzed the issue of home schooling, and its relationship with the above mentioned educational ideology of the Constitution, in order to determine what is the purpose of education.

Secondly, and given that the Constitutional Court considers that education has a purpose of social integration that goes beyond the transmission of knowledge, civic aspect of education is analyzed, from the controversy generated by the introduction into the curriculum of the subject «Education for Citizenship».

Third, and in view of the constitutional relationship between ideology and institutional education is considered the legitimacy of the schools specialized by sex.

Finally, from the considerations in the above cases, is proposed a restrictive conception of the educational ideology of the Constitution in order to preserve political pluralism and the distinction between state and society, basis of a democratic society.

\section{Palabras clave:}

Derechos fundamentales, libertad de enseñanza, ideario educativo constitucional, igualdad, pluralismo político.

\section{Key words:}

Fundamental rigths, freedom of education, educational ideology of the Constitution, equality, political pluralism. 